\title{
Centrifugal Pump Performance Characteristics for Domestic Application
}

\author{
Aisyah Jilani ${ }^{1}$ and Akhtar Razali ${ }^{*}$ \\ ${ }^{1}$ Faculty of Mechanical Engineering, Universiti Malaysia Pahang, 26600 Pekan, Pahang, Malaysia
}

\begin{abstract}
Water pressure problems at home can be quite frustrating in daily life which is comes in different ways of complication. It may take forever for the faucets to fill a bathtub, or a slow spray shower head and longer time taken for the washing machine to run a cycle. The problem can be fixed by installing a pressure booster pump. This research is embarked to study on a centrifugal pump performance with a view to analyse pressure built-up and flowrate in pipe at fixed speed. A simple and inexpensive test rig is developed to resemble water distribution for domestic use; i.e. house application. The method is then experimentally validated to measured and analysed the pump performance such as water pressure, water flowrate, power of pump and pump speed. Since the centrifugal pump are added, the pump is able to boost the water flowrate. However, since the centrifugal pump work at constant speed, the water pressure in pipe is high when the water demand is low. The maximum pressure inside the pipe was 28.24 psi which quite high and exceed the piping standards. Power consumption also remained constant approximately $0.500 \mathrm{kWh}$ when water demand was low which led to energy wastage.
\end{abstract}

\section{Introduction}

Water is plentifully available natural resource on earth and can be renewable. $70 \%$ of the Earth's surface are covers with water but only portable for 3\% of the water. Water has been used for multiple purpose such as agricultural field, industrial usage and domestic purposes. The speedy development of technology and science improved the flow meter designs and other sensors to attain good water supply through pipes and storage tanks [1]. A pump is a machine that expends energy which is to increase the water pressure and move it from a point to another point. A centrifugal pump transmit energy to the liquid which means a centrifugal force that produced by the rotating impeller [2]. It is also increase the pressure by converting mechanical energy from the motor to the water through the rotating impeller. The water discharge from the inlet to the centre of impeller and exit along its blades. The force of centrifugal hereby boost the water velocity and also transformed the kinetic energy to pressure consequently. Centrifugal pump is also a type of kinetic pump that used in applications that requires moderate-to-high and low pressure flow. Generally centrifugal pump is ruling equations that are based on energy conservation law [3-4]. It is also widely

\footnotetext{
*Corresponding author: akhtar@ump.edu.my
} 
used because of their head, design simplicity, high efficiency, smooth flow rate, ease of operation and maintenance and wide range of capacity [5].

The major advantages of a centrifugal pump also includes its higher operating speeds, lifting highly viscous liquids for example muddy and sewage water, oils, chemicals, sugar molasses, paper pulp, and higher discharging capacity which are against with the reciprocating pumps which only can handle small quantity of liquid relatively operating at comparative slower speeds that is limited to pure water or less viscous liquids that free from impurities limited in considerations of separation, frequent choking troubles and cavitation [6-7]. The differential pressure or head created by the pump is used to transmit energy to the water, and overcome the frictional losses in the piping system. The pump itself also acquire energy losses at the impeller, bearings and casing. Thus, the useful power that composed by the pump is only part of the power that used to its shaft from the motor [8-9]. The centrifugal pump also widely used for domestic application that applied as water booster at home which eject the water rapidly to all valves through the piping system.

The centrifugal pump characteristic curves show the law and relationship of each parameter, and it is the pump performance expression, which has significant function in production process. The quantity of flow (Q) and the pump head $(\mathrm{H})$ are two major parameters among the performance parameters of the centrifugal pump. The H-Q curves shape have a direct effect on the stability operation of centrifugal pump and flow regulation range. This pump also need a variable value of torque based on speed. In simple way, torque is proportional to the square of the speed which is when the speed is doubled, so the torque is raised by a factor of four $(22=4)$ [10]. The consumption of energy in a centrifugal pump system highly rely on an electric drive. For example, at a constant speed operation, it is mandatory to use throttle valves to regulate either the pressure or flow but it was old method and used a lot of energy which is lead to energy crisis [11-12].

\section{Methods and equipments}

There are two factors for methodology which are various pipe opening and the number of pipes open to see the pressure drop. In this experiment, the static head was neglected. Several steps were taken to analyse the centrifugal pump operation with multiple valves. The first step is to install the experimental rig that contains sensors to measure flow rate and pressure, Arduino UNO microcontroller, power analyser, centrifugal pump, piping setup that similar to what is in a terrace house, a tank and 6 valves. Arduino is an open source hardware and software platform that build on the ARM micro controller and Atmel A VR. Due to its cheap price, flexible and convenient, rapid development and widely used application, especially in many system prototype based on design of sensor [13]. An Arduino can read information from input devices such as Sensors, Antenna, Trimmer(potentiometer) and others and also can send information to output devices for example LCD Screen, LED, DC motor and speakers [14]. Secondly, setup coding for sensor in the microcontroller to display the value that read by the sensor. The last step is testing run the pump for few minutes and check the value that displayed on LCD.

The water flowed from the water tank and move to the centrifugal pump which conversion of energy happened. The pump that was used in this work are DSH3 (702-24pc) model which operated with power of $0.7 \mathrm{hp}-0.5 \mathrm{hp}$. The pump converts the rotational kinetic energy to the hydrodynamic energy of the water flow and accelerate the water by the impeller outward to the exits which is called diffuser. Fluid that flow rapidly exit from the pump then go through the flowrate sensor and the value of water flowrate are displayed on LCD. Flow rate can be defined likely by various techniques like difference in velocity or kinetic energy. In this experiment, flow rate is determined by change in water velocity. Velocity of the water depends on the pressure that forces through the pipelines. As the cross-sectional area of pipe 
is known and remains unchanged, the average velocity is a prefiguration of the flow rate [15]. Next, the water goes through the pressure sensor that attached with the Arduino microcontroller and the pressure gauge which flow exit to the open valves. Microcontroller is used to monitor the sensor with which LCD is interfaced to display the flow rate of water and water pressure in pipe. The direction flow of water is illustrated in the schematic diagram shown in Figure 1.

6 valves are used to test the water pressure and flowrates which is represent as water tap or shower in a terrace house as illustrates in Figure 2. The valves are open one by one to analyse the water flowrate and pressure in pipe. There are two types of valves opening which are half open and full open. The pipes are open for an hour to get the energy and power value to see the pump performance.

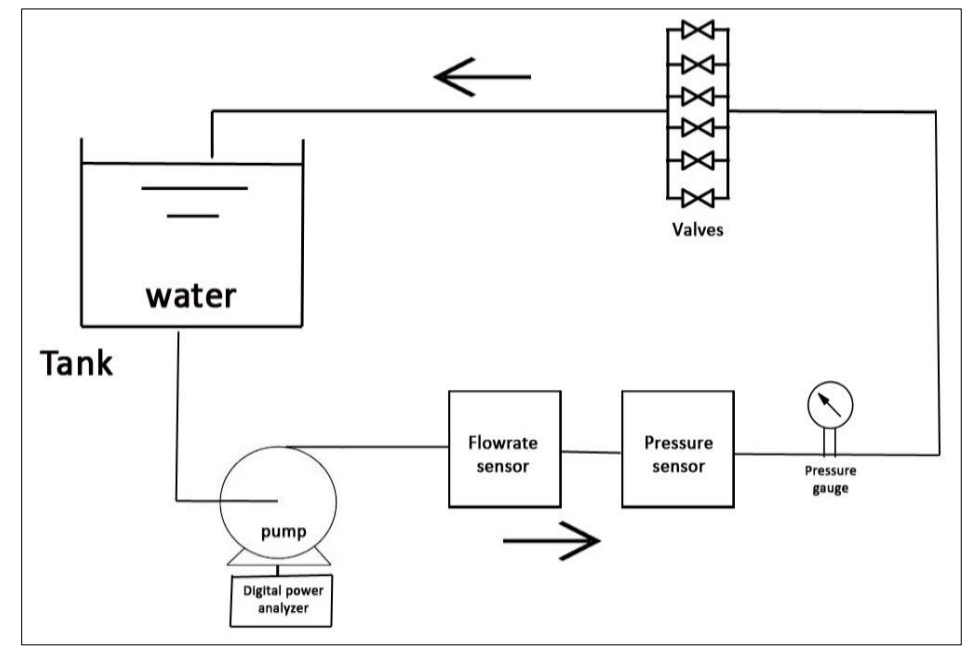

Fig. 1. Schematic diagram of experiment flow.

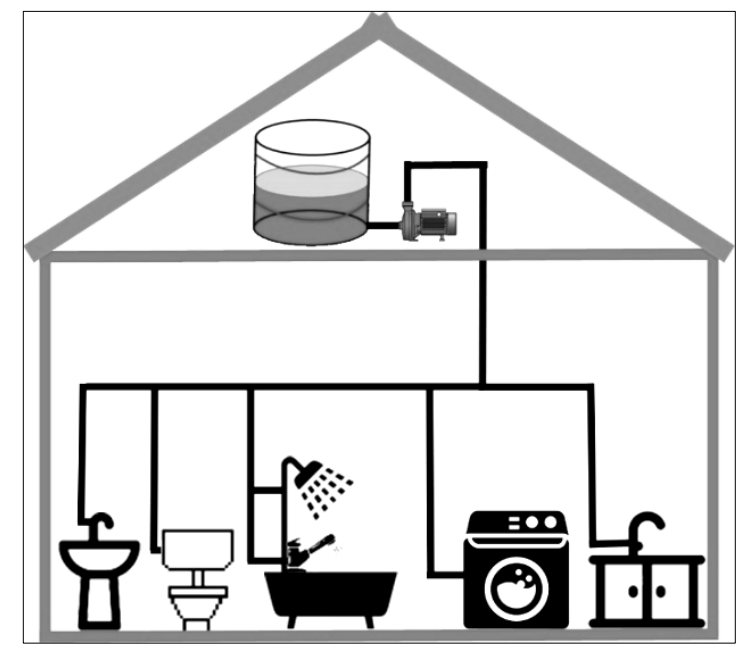

Fig. 2. Piping of water distribution in a terrace house. 


\section{Results and discussion}

The data results obtained from the experimental rig testing can be seen in Table 1 which displayed the value of water pressure and water flowrate based on the quantity of pipe that open synchronously. To differentiate the pressure and water flowrate, the experiments was also performed at two types of valve opening which are half open and full open as stated in the Table 1. The power of each number of valves have small difference gaps probably due to tolerance of the device itself since the pump horsepower is around $0.7-0.5 \mathrm{hp}$ and been tested for an hour. The power of the pump remains constant since the speed of the pump remain unchanged even the pressure, flowrate and number of pipes are fluctuating.

Table 1. Pressure, flowrate and power reading.

\begin{tabular}{|c|c|c|c|c|}
\hline \multicolumn{2}{|c|}{ Valve open } & Pressure (psi) & Power (kWh) & Flowrate (lpm) \\
\hline \multirow{2}{*}{ 1 valve } & Half & 28.24 & 0.508 & 16.38 \\
\cline { 2 - 5 } & Full & 10.01 & 0.506 & 27.79 \\
\hline \multirow{2}{*}{ 2 valves } & Half & 18.15 & 0.505 & 24.88 \\
\cline { 2 - 5 } & Full & 4.50 & 0.509 & 32.13 \\
\hline \multirow{2}{*}{3 valves } & Half & 9.50 & 0.507 & 29.70 \\
\cline { 2 - 5 } & Full & 3.11 & 0.503 & 33.34 \\
\hline \multirow{2}{*}{4 valves } & Half & 5.27 & 0.504 & 33.59 \\
\cline { 2 - 5 } & Full & 2.70 & 0.501 & 33.68 \\
\hline \multirow{2}{*}{5 valves } & Half & 4.64 & 0.500 & 33.86 \\
\cline { 2 - 5 } & Full & 2.52 & 0.508 & 34.59 \\
\hline \multirow{2}{*}{6 valves } & Half & 3.77 & 0.503 & 34.51 \\
\cline { 2 - 5 } & Full & 2.08 & 0.502 & 34.67 \\
\hline
\end{tabular}

The graph as seen in Fig. 3 illustrates the pressure and water flowrate in pipe for certain number of valves open. It can be seen that half open and full open valve have similar pattern which are the pressure decrease as the number or valve open increase. In Fig. 3 also, the water flowrate increases when the number of valves open increase. For fully open valve, flowrate gap difference is bigger than half open valve. The less number of valve open, the higher the pressure inside the pipe. This is because, the less number of valve open, the smaller the cross sectional area of opening valve which increased the pressure inside the pipe and restrict the water to flow out and naturally slowing down the water flow rate.

An open valve has the same value of power consumption with the maximum open valve which lead to wasteful energy and power consumption. Moreover, with power $0.50 \mathrm{hp}$ for a single open valve, it decelerates the water flowrate inside the pipe and put extra pressure to the pipe surface and probably can cause leakage. High water pressure may feel goof in the shower, but the stronger the water hits the inside of the pipes, the bigger the risk of eventual leaks. In utmost cases, incorrect water pressure inside the pipe can cause pipes to burst. In more regular cases, excess water pressure causes taps or fixtures to leak sporadically. When water pressure is too high, water starts to drip out of taps, toilets, and showers. Over an extended period of time, the loss of water can add up to a lot of water and as a precious resource, water should be conserved [16]. High water pressure start to erode the pipes and over the time can caused major damage to household plumbing. The 'water hammer' term is 
used to describe the loud banging noise when highly water pressure encounters a valve. For half open valve case, the smaller the opening of the valve, the slower the water flowrate. The reduced flow rate would reduce the pressure loss in the pipes, which resulting in more pressure.



Fig. 3. Graph of pressure in pipe and water flowrate for half and full open valve.

\section{Conclusion}

This experiment was done particularly to analyse the use of centrifugal pump which is constant speed pump for domestic application. The experimental observation showed that constant speed pump has high water pressure especially for low water demand which decreased the lifespan of the pump because of overworked and lead to pipe leakage due to over pressured in the pipe caused by the fluctuating water demand in a house. The maximum pressure was 28.24 psi which is quite high and exceed the standards in water distribution piping. The data also showed that the energy of the pump produced were maximum value $0.509 \mathrm{~kW}$ even for low water demand which caused high power and energy wastage. Constant-speed systems have served the industry and residential area well for many years, but technological enhancements increase just like the consumer's energy utility bill. Therefore, more experiments are needed to extend the lifespan of the centrifugal pump for example by creating variable speed system. With the pressure on the consultant to improve the system for energy efficiency, the variable-speed system has turn into fascinating option in the 21 st Century economy. 


\section{References}

1. R. Hosamani, R. Bagade, International Journal of modern trends in engineering and research 2, 7 (2015)

2. Pumps, World, Back to Basics with Centrifugal Pumps, World Pumps 2010, 6, 30-31 (2010)

3. A. Hasan, B. K. Hussain, L. Alzubaidi, A. El-Gizawy, 2017 Annual Conference on New Trends in Information \& Communications Technology Applications (NTICT), $310-315$ (2017)

4. S. Corlman, Reducing Energy Waste in Centrifugal Pump Systems through the Implementation of Bep Optimized Pressure and Flow Control, University of Missouri, Columbi, 1-148 (2015)

5. P. Girdhar, O. Moniz, S. Mackay, Practical Centrifugal Pumps (2005)

6. A.Suhane, International Journal of Engineering Research and Applications 2, 4, 1823 29 (2012)

7. B.Durrer, F.H. Wurm, W. AG, WSEAS Int. Conference on Applied and Theoretical Mechanics, 203-07 (2006)

8. M. I. Jahhmeerbacus, Industrial Engineering and Operations Management (IEOM), 1-6 (2015)

9. T. Ahonen, J. Tamminen, J. Ahola, J. Kestila, 13th European Conference on Power Electronics and Applications EPE '09, 1-10 (2009)

10. X. Zibin, Intelligent Systems Design and Engineering Applications (ISDEA), (2016)

11. L. Gevorkov, V. Vodovozov, Compatibility, Power Electronics and Power Engineering (CPE-POWERENG) (2017)

12. P. Francesco, P. Bertoldi, Energy Efficiency in Motor Driven Systems, Springer Science \& Business Media, 1-565 (2003)

13. Y. Wang, Z. Chi, Instrumentation \& Measurement, Computer, Communication and Control (IMCCC), 770-73 (2016)

14. Y. A. Badamasi, Proceedings of the 11th International Conference on Electronics, Computer and Computation (ICECCO), 1-4 (2014)

15. N. R. Kolhare, P.R. Thorat, International Journal of Engineering Research \& Technology (IJERT) 2, 1-4 (2013)

16. N. Samir, R. Kansoh, W. Elbarki, A. Fleifle, Alexandria Engineering Journal, 56, 601612 (2017) 